\title{
A relação entre mediação e uso no campo de pesquisa em informação e comunicação na França
}

DOI: 10.3395/reciis.v3i3.276pt

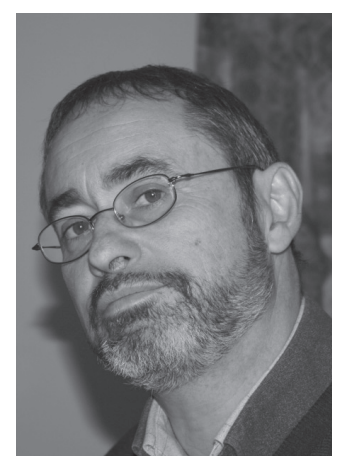

Yves Jeanneret

Laboratório de Cultura e Comunicação, Université d'Avignon et des Pays de Vaucluse, Avignon, França

yves.jeanneret@univ-avignon.fr

\section{Resumo}

As noções de « mediação » e « uso » são empregadas freqüentemente nas pesquisas em ciências da informação e da comunicação na França. O principal objetivo deste artigo é de refletir sobre essas duas noções, a fim de revelar, por detrás de sua evidência «natural », alguns problemas, recursos e riscos. A idéia de mediação tem origem nas ciências antropo-sociais e fornece meios para descrever, com uma certa precisão, os processos de informação-comunicação; ela permite requalificar socialmente as dinâmicas e os regimes da cultura ; leva o pesquisador a problematizar o seu lugar próprio na circulação social dos saberes. A idéia de uso mantém um elo histórico com os estudos de recepção das mídias realizados pela sociologia "administrativa" norte-americana e evoca a funcionalidade, mesmo que não se objetive reduzi-la à tecnologia. A (as) mediação (mediações) e o uso/use não se distinguem tanto entre si pelos seus respectivos objetos, mas pelo efeito de perspectiva que produzem e a maneira muito diferente de entrever o lugar da comunicação nas práticas informacionais. Pode-se então afirmar que, numa perspectiva comunicacional, as noções de mediação, de prática e de uso atuam conjuntamente. O que não se realiza, contudo, sem tensões e paradoxos.

\section{Palavras-chave}

uso; mediação; escrita; traços de escrita;informação; comunicação

\section{Introdução}

Neste trabalho, irei concentrar-me em duas noções às quais se faz referência em vários trabalhos diferentes sobre processos informacionais e comunicacionais. Em francês, essas noções são chamadas de "médiation" e "usage": as quais podem ser traduzidas de forma aproximada para o inglês como mediation (mediação) e use (uso). Gostaria de apreender essas duas noções de forma problemática, a fim de desconstruir, se possível, sua aparente naturalidade. O interesse de tal exame é apontar alguns recursos e também alguns riscos que tal terminologia coloca.

Devo indicar que abordo esta questão de forma limitada. Pertenço a comunidades de pesquisa das pessoas que buscam compreender algumas práticas comunicacionais particulares: aquelas que buscam o compartilhamento de conhecimento e de objetos culturais na sociedade [que buscam analisar os dispositivos, as práticas, os discursos por meio dos quais os saberes 
e os valores culturais circulam entre espaços sociais diferentes.] É o que chamo de, sem qualquer sentido pejorativo, "trivialidade".

A principal vantagem deste campo de pesquisa é que é inclassificável. Quando se examina o desenvolvimento da popularização de livros [Quando estudamos os livros de vulgarização] ou a exposição de textos literários nas paredes do metrô, por exemplo, é impossível dizer se o objetivo é a informação ou a comunicação. Devo dizer que a situação institucional do campo francês das ciências sociais enfatiza fortemente esta situação. De fato, ela possui a particularidade de juntar numa única disciplina vários tópicos que, em outra parte, são comumente divididos em ciências separadas, especialmente em países de língua inglesa: ciência da informação, ciência da comunicação, estudos de mídia, estudos culturais, etc. É com base nessa particularidade que tenho a oportunidade, aqui, de questionar algumas noções mencionadas acima. Meu objetivo é introduzir algumas hipóteses sobre a forma como funcionam ambas as noções num espaço tão info-comunicacional.

Primeiramente, devo apontar que as noções de mediação e uso não têm um papel equivalente na análise de processos de informação e comunicação. Portanto, será necessário perguntar se podem funcionar juntas e como poderiam fazê-lo, de um modo sinérgico ou conflituoso. Finalmente, poderemos considerar a maneira pela qual todas essas questões aparecem num campo mais limitado, o de práticas de escrita, um campo no qual a relação entre mediação e uso possui um impacto especialmente decisivo.

\section{Mediação/mediações}

A palavra francesa "mediação" é tão freqüentemente utilizada no singular (médiation) como no plural (médiations). A pesquisa deve, de fato, questionar tanto o sentido social do ato de mediação em si quanto realizar um inventário preciso dos múltiplos tipos de mediações e dos diferentes tipos de mediadores. O conceito de mediação vem dando apoio à disciplina francesa de ciências da informação e comunicação há duas décadas. Ele não foi criado por esta disciplina, mas esta disciplina atraiu indivíduos que se aplicam a revelar que nada é transparente. Pessoas que apontam que nada é realmente imediato e que destacam o papel de intermediários, mediadores, nas realidades sociais. Pessoas que demonstram que o conhecimento e o significado nunca nos são simplesmente dados, mas precisam ser elaborados. De outras maneiras, a disciplina francesa de ciências da informação e comunicação alimenta-se de uma certa forma de negatividade: ela recusa deliberadamente uma abordagem imediata, transparente ou absoluta de fatos da cultura: o que Barthes chamou de "naturalização" de práticas culturais. Mas tal negatividade leva a uma positividade correspondente: a maneira pela qual os mesmos pesquisadores se comprometem a revelar, distinguir e descrever todos os objetos e seres intermediários na comunicação. A determinação que mostram em não dar nada como certo.
Tal postura é mais fácil de ser adotada em algumas áreas sociais do que em outras. Conseqüentemente, a disciplina tende a se dividir em diferentes apreensões da questão da mediação, de acordo com as atitudes dominantes que terminam por prevalecer em domínios científicos próximos. Por exemplo, os sociólogos da cultura possuem uma longa experiência no estudo de mediações e mediadores: é uma tarefa comum para eles tentar repovoar mundos da arte. Nesse sentido ela oferece recursos importantes às ciências da informação-comunicação. Contrariamente, a ciência política concorda muito relutantemente com a idéia de mediação em si, a qual normalmente deveria eclipsar a realidade de relações de poder.

É a razão pela qual a própria noção tornou-se profundamente discutida dentre os pesquisadores. Como uma categoria antropológica, a idéia de mediação transmite um conceito de cultura; como um item profissional, é aplicada a uma grande variedade de dispositivos, ações e tarefas; como uma ferramenta conceitual, dá suporte à possibilidade de descrever os diferentes componentes de qualquer processo comunicacional (DAVALLON, 2004). A ciência da informação e comunicação alimenta-se de tal circulação entre as diferentes dimensões daquela noção complexa. Há tempos vários atos de mediação têm sido realizados por diversos atores; mais recentemente, diferentes dispositivos de mediação (de natureza distinta) foram desenvolvidos, bem como programas, procedimentos e artefatos educacionais, de forma que a idéia de mediação tornou-se uma realidade profissional e, de certa forma, uma realidade política. De qualquer forma, nenhum desses gestos, estando relacionados a amadorismo ou a empreendedorismo ou a habilidade, deixa de transmitir uma dimensão simbólica aos atos sociais (DUFRÊNE \& GELLEREAU, 2001). Eles prosseguem delineando objetos, definindo relações com a cultura, fomentando posturas, legitimando normas.

Posso mencionar aqui um exemplo dentre mil: o da iniciativa tomada por várias associações a fim de promover a capacidade de leitura de pessoas menos favorecidas (BONACCORSI, 2009). Somente pelo fato de existirem, esses projetos contribuem para estimular uma formação de discurso sobre a necessidade social de um "dever de leitura": um valor cultural no qual a idéia de mediação está constantemente renascendo e se renovando. Mas conforme se deixa a moldura normativa do projeto em direção à elaboração das ações e depois às suas publicações, pode-se descobrir uma rede de atores, cada qual utilizando roteiros, programas, meios para tornarem-se invisíveis. Finalmente, a fim de compreender a operatividade efetiva de todo o processo mencionado acima, é preciso utilizar a mediação como uma categoria analítica, a fim de descrever exatamente o contexto material, as produções semióticas, bem como as formas de interações. A forma pela qual o status da leitura é elaborado numa sociedade baseia-se numa rede semelhante de valores, de papéis sociais e de formas simbólicas.

Tal exemplo mostra a base tripla sobre a qual a noção de mediação funciona numa disciplina como a ciência da informação e comunicação. Ele oferece algu- 
mas ferramentas para uma descrição exata de processos comunicacionais; permite qualificar socialmente as dinâmicas e regimes de cultura; impulsiona os pesquisadores a questionar seu próprio lugar no processo social de circulação do conhecimento.

A primeira figura da noção de mediação é uma de procedimento. As distinções que possibilita fortalecem a análise dos processos comunicacionais: como, por exemplo, a distinção entre mediações sociais, pragmáticas, semióticas, técnicas, etc. Por exemplo, se aceitarmos sem análise a crença de que as tecnologias de rede podem criar comunicação imaterial - o que é encorajado pela fórmula discursiva de "sociedade da informação" -, estaremos mais inclinados a opor o real e o virtual, por exemplo, a cidade real e aquela virtual. Por outro lado, se analisarmos como tal discurso se difunde em vários espaços, os meios que usa para se tornar visível e legítimo, nos tornamos capazes de apontar uma atividade complexa que é exposta a fim de fazer a ligação entre diferentes espaços de comunicação, utilizando artefatos materiais, movimentos de pessoas, procedimentos de discurso (LABELLE, 2007). A chamada cidade digital não é uma cidade separada, mas um conjunto de projetos, de códigos, de dispositivos que personificam e espacializam a utopia de uma possível vida livre da realidade. Sociólogos nos sugeriram um caminho para entender isso, conforme evocaram registros que mudam de um lugar para outro (o que chamam de móveis imutáveis) e nos convidam a viajar pelas cadeias de sujeitos e objetos para compreender como as realidades sociais são estabelecidas (LATOUR, 1996). Entretanto, nós, pesquisadores da ciência da informação e comunicação, temos algo a acrescentar a tal modelo, especialmente porque não assemelhamos o processo de mediação a uma cadeia: tentamos distinguir entre dispositivos materiais, suportes de escrita, documentos, formas textuais, lugares comunicacionais. Em resumo, nós não somente postulamos algo como a mediação, mas tentamos identificar vários tipos de mediações e entender como cada uma exige atividade, bem como gesto, interpretação e expressão. Se você consegue identificar realidades documentais (como a lista), formas semióticas (como o rótulo de qualidade) e figuras retóricas (como a narrativa emblemática), você consegue não somente identificar como pessoas diferentes agem, mas questionar como a ação em si deve ser definida.

$\mathrm{Na}$ verdade, o objetivo de descrever processos de informação necessita do estudo de um complexo de objetos através dos quais as dimensões sociais, simbólicas e técnicas da comunicação são constantemente trocadas. Nesse primeiro sentido, a noção de mediação luta contra a ilusão de transparência.

Em segundo lugar vem a figura social de mediação. O exemplo acima mostra que ao ligarem-se formas sociais, semióticas e técnicas, chega-se a uma compreensão particular de questões sociais e políticas. Ao invés de realizar somente vários conluios óbvios entre atores, é possível descrever uma nova relação entre a obrigação de fazer e a habilidade de dizer. O primeiro resultado de uma análise de mediações é conferir existência a alguns atores os quais uma abordagem acadêmica da cultura negligencia sistematicamente, tal como, por exemplo, aqueles que popularizam a ciência de resumir um campo de conhecimento. Mas, de forma mais profunda, a idéia de mediação leva a uma elucidação do que faz os dispositivos e situações comunicacionais operantes, o que chamamos em francês de "opérativité symbolique” (QUERE, 1982). O sentido é como geram uma representação do nosso mundo, pontos de vista sobre ele, papéis perante ele. Da mesma forma, chamamos de "operacionalidade social" (DAVALLON, 1999) a forma como esses sistemas e contextos implicam em envolvimentos institucionais, atraem públicos, reconhecem autoridades. Um texto, uma figura, uma interface de recuperação de informação, por exemplo, geram representação, isto é, fornecem uma mediação à nossa experiência. Eles são aparatos de representação ("dispositifs de representation", MARIN, 1981): conferem existência tanto a uma concepção de realidades sociais ("effet de sujet") quanto a uma postura para sua percepção. O livro dá existência ao leitor, a fotografia à testemunha, as plataformas colaborativas ao engenheiro social.

Nesse segundo sentido, a noção de mediação tira sua virtude produtiva do fato de que ela luta contra o tópico da grande lacuna, entre realidade e virtualidade, entre tradição e cyber cultura, entre "web 1.0, 2.0, 3.0, 4.0...".

A última figura que eu gostaria de mencionar é a da reflexividade. Estando consciente das mediações, o pesquisador, o especialista e o ator têm de levar em consideração os procedimentos pelos quais produzem seu próprio conhecimento. A pesquisa em ciências atropológicas-sociais não é de forma alguma um discurso isolado. Ele progride interagindo com o discurso social. Ele o captura, analisa, torna visível e dá publicidade. $\mathrm{O}$ que leva a uma importante exigência: levar em consideração o fato de que os conhecimentos sobre informação e comunicação se difundem em vários contextos sociais, onde são elaborados, transformados, utilizados. Como pesquisador, ninguém está totalmente livre para decidir qual sentido deve ser dado a uma determinada prática. Tivemos que lidar com essa restrição durante um trabalho de campo sobre leitura na internet (SOUCHIER et al., 2003). Alguns dos usuários de redes de informática vêem um web site como veriam um documento: eles procuram um autor, um texto, uma garantia. Outras pessoas, ao contrário, vêem a Internet como um tipo de tanque no qual está estocada uma coleção de dados pontuais, sem qualquer ligação entre eles. É o que eu chamo de "predileção semiótica": qualquer usuário está em condições de definir o que deve ser interpretado e, além disso, de decidir se o objetivo é interpretar um texto ou lidar com um objeto. Num estilo de pesquisa tão reflexivo, pode-se compreender que estamos longe da capacidade de fazer afirmações decisivas, mesmo que vagas, sobre o fato, por exemplo, "ninguém lê na Internet"... Tal proposição de fato não faz sentido se não nos esforçarmos para explicitar e testar nossas próprias hipóteses sobre o que as pessoas consideram legível e, de forma mais ampla, interpretável. Isto porque os pesquisadores não enfrentam o processo de compartilhamento social de forma 
puramente externa, como simples observadores. Atores políticos, bem como técnicos e financeiros, tem um papel na escolha entre diferentes predileções semióticas, fomentando algumas delas e evitando outras.

Quando voltada para a comunidade científica como uma interrogação reflexiva, a mediação luta contra a ideologia clássica de popularização (em francês "vulgarisation", com uma conotação algo pejorativa): uma concepção de comunicação como uma transferência de conteúdos de informação de pessoas instruídas àquelas ignorantes. As mediações sócio-cognitivas dos processos de informação têm a conseqüência de que as realidades sociais que a pesquisa procura analisar são constantemente elaboradas por atores e que elas não poderiam existir sem a intervenção deles. Elas podem até desaparecer se as pessoas deixarem de apoiá-las.

\section{Uso ("usage")}

A noção de uso tem um status algo diferente na ciência da informação-comunicação francesa daquele da mediação, por um conjunto de razões as quais mencionarei primeiro.

Mesmo que a idéia de uso seja bastante tradicional nas ciências da documentação, sua presente legitimidade (muito forte) não vem da ciência da informação e comunicação. A noção de uso é historicamente ligada à sociologia da mídia, especialmente as averiguações sobre públicos midiáticos, no campo da pesquisa "administrativa" americana. A tendência científica conhecida como "pesquisa do uso e gratificação" teve um importante papel na afirmação da liberdade do "receptor" lidando com as mensagens midiáticas. Na França, os termos "usage" e "usager", os quais são possíveis traduções, dentre outras, das palavras inglesas "uso" e "usuário", possuem uma história científica muito rica. Elas foram notadamente elaboradas, de forma algo diferente, pela abordagem crítica de poderes culturais, com as investigações sobre leitura, consumo, cultura técnica, cujo objetivo era tornar visível a parte invisível de culturas comuns (DE CERTEAU, 1990; PERRIAULT, 1989). Finalmente, a noção encontrou status renovado conforme foi incorporada aos projetos importantes de inovações técnicas, como dispositivos de telecomunicação e comunicação mediada por computador. Na França, a criação de um laboratório de pesquisa industrial e de desenvolvimento sobre as utilizações dos objetos técnicos (CNET) gerou um estilo específico de trabalho e, inevitavelmente, produziu toda uma pré-construção intelectual da noção.

Nestas condições, não é absurdo dizer que a noção de uso freqüentemente faz parte daquela de mediação e, de forma mais ampla, de todo um campo de noções utilizadas em ciências sociais, tão logo quanto a questão seja sobre gerenciamento ou financiamento de atividades de pesquisa. Como um pesquisador que estudou nos anos 1970, estou muito surpreso pelo modo como a idéia de uso ofuscou recentemente a noção de prática.

Outra diferença entre as noções de mediação e uso refere-se ao fato de que a segunda foi desenvolvida diretamente num espaço científico poliglota, o qual era primariamente dominado por falantes do inglês, o campo de inovação nos processos técnicos. Mas não é pequena a diferença entre os recursos que cada língua oferece à manifestação de idéias subjacentes ao uso de tais termos. $\mathrm{O}$ inglês pode utilizar tanto o verbo quanto o substantivo: use/to use (uso/usar). O francês precisa escolher entre dois verbos diferentes ("user" ou "utiliser" - usar/utilizar) e dois substantivos diferentes ("usage" e "utilisation" - uso/ utilização). Este é o motivo pelo qual os recursos léxicos franceses levaram a um tipo de nebulosa semântica. Quando se utiliza a palavra "use”, pode-se sempre ser compreendido como falando sobre uma questão funcional (como você opera?) ou simbólica (qual a questão?), e esse tipo de status ambíguo foi muito importante ao ajudar o projeto sociológico a sobreviver em contextos industriais. Em compensação, tal ambigüidade não evita a produção de um desvanecimento epistemológico permanente. De fato, assim como declarar que se dará atenção aos usos sociais de artefatos tem o poder de ativar o financiamento a pesquisa, nenhum grupo de pesquisa esquece-se de protestar que são especialistas em estudos de uso. O resultado é o crescente número de projetos e relatórios que, com o título de estudos de uso, não incluem nenhuma análise documental e nem qualquer trabalho de campo etnográfico merecedor desse nome.

Em outras palavras, a noção de uso, diferentemente daquela de mediação, não se encaixa facilmente com a idéia de comunicação. A idéia de uso tende a levar à de funcionalidade, mesmo se não tentarmos reduzi-la à técnica. Em nossa representação visual, um estudo sobre uso e usuário sugere a cena de uma pessoa que se defronta com um aparato que consegue operar ou não. Qualquer um pode verificar, nos grandes programas $R \& D$, no discurso de gerentes industriais, bem como em políticas públicas sobre o equipamento de instituições culturais e de informação, um privilégio é sistematicamente ligado ao que o sociólogo francês Flichy chama de "estrutura de funcionamento" (FLICHY, 1995), comparado com as partes simbólicas, afetivas, estéticas ou ideológicas das práticas. Para tanto, muitos estudos de pesquisa de ciência da informação e comunicação sobre usos sociais de dispositivos de comunicação são financiados como uma forma de extensão de projetos exclusivamente técnicos, diferente das investigações longas e prolongadas sobre usos culturais lideradas por De Certeau trinta anos atrás. Ao escapar do campo das práticas culturais para aquele da apropriação mais ou menos fácil de objetos técnicos inovadores, a palavra "uso" perdeu em exatidão o que ganhou em popularidade.

A comunidade de sociólogos do uso teve que resistir a essa lógica. Eles propuseram uma frase para manifestar a complexidade do problema, a abordagem "sócio-técnica" (socio-technique) dos usos. Mas tal fórmula não é suficiente para evitar o paradoxo. Se colocarmos de um lado a técnica e do outro a sociedade - mesmo se recusarmos a própria oposição -, não conseguiremos compreender como a mediação se refere a símbolos, discurso ou representação. Utilizar um livro, um computador ou um telefone celular não pode ser reduzido a uma combinação pura de lógica social e propriedades técnicas. Objetos desse tipo são 
mídia, isto é, objetos que não somente unem realidades sociais como as geram. Para nós, pesquisadores da ciência da informação e comunicação, é impossível comparar os objetos técnicos da comunicação a outros. Algo com que concordam os semióticos (BADIR, 2007). Esses objetos são mídia: é claro que são artefatos, mas artefatos particulares que não somente moldam como os seres humanos dominam as forças naturais, mas também os meios da representação. Então somos levados de volta à mediação. É um ponto sensível em nossa própria disciplina, na qual algumas tendências em pesquisa, as quais não se interessam por problemas informacionais, se contentam com o conceito de "tecnologia". Entretanto, sejam computadorizadas ou não, a mídia não é só ferramentas simples. Seu uso não depende somente da ergonomia. Ou, mais precisamente, depende de uma ergonomia de natureza muito especial. A questão é muito importante para aqueles que analisam ou gerenciam processos de informação. Pois a produção simbólica de informação e conhecimento é freqüentemente retratada sob a forma do uso prático de várias ferramentas, através de como essas ferramentas dão acesso a mercadorias e se adequam às diferentes expectativas de "usuários finais".

Em outras palavras, para tornar o problema do uso cientificamente proveitoso no campo da ciência da informação e comunicação, é preciso reformulá-lo. Se alguém aceita um forte conceito de informação e comunicação, deve compreender como idéias, conhecimentos e representações podem ser elaborados. A meu ver, a condição para isso não é tomar o termo "uso" como sendo simplesmente equivalente ao de "prática”, mas fomentar uma comparação entre ambas as noções. Para mim, os usos sociais são não somente um componente das práticas sociais, referindo-se às situações nas quais as pessoas precisam lidar com objetos que outras pessoas projetaram. Desse ponto de vista, não devemos mencionar usos da informação, mas sim práticas informacionais que levam atores sociais a deparar-se com artefatos produzidos por outras pessoas: isto é, especialistas em informação, engenheiros, amadores, pessoas que trabalham com marketing etc.

À medida que nossa abordagem baseia-se naquela idéia simples, temos que nos perguntar qual é conceituação de práticas culturais e informacionais à qual recorremos cada vez que planejamos analisar o uso de objetos culturais, dispositivos de informação, trabalhos ou textos.

As considerações acima levantam a questão do ponto de vista e da escala que escolhemos para observar os usos sociais de objetos. É claro que o principal ponto forte dos estudos de usos (o fato de que realmente fazem trabalho de campo) não pode ser distinguido de seu ponto fraco, o risco em potencial de tomar a parte visível das práticas pela realidade inteira. Uma investigação que se concentra numa tecnologia midiática específica (por exemplo, os usos das fotografias no telefone celular) não traz o mesmo tipo de conhecimento que uma investigação que começa a partir de práticas culturais: por exemplo, de práticas musicais, de relações pessoais com a ciência, de vidas sentimentais. A primeira se apóia na hipótese de que práticas culturais dependem das funcionalidades de um objeto, enquanto a segunda se distancia dos objetos, arriscando tornar-se incapaz de ver o que ocorre neles. Pode-se considerar que um ponto de vista ideal seria combinar ambas as perspectivas, mas não há ponto de vista total em nenhuma prática.

Então enfrentamos mais uma vez a dimensão política de nossa questão. Estudos de uso não são somente formas de investigar práticas culturais, eles participam da produção de uma representação da sociedade, em sentidos tanto cognitivos quanto políticos. Por exemplo, se um estudo de uso chega à conclusão precipitada de que as "pessoas" esperam algo, ele cria uma entidade coletiva que é mais ou menos baseada na metodologia investigativa, mas nunca simplesmente reflete as pessoas que foram entrevistadas ou observadas. Uma pessoa tão moral irá então adquirir, independentemente de qualquer procedimento político, o status de uma representação de uma comunidade. Portanto o estudo de uso produz valores e representações, para então personificar essas construções em alguns aparatos que estão destinados a modificar a própria estrutura das nossas vidas culturais e informacionais e para abrirem-se num ecossistema info-comunicacional.

\section{Uma dialética complexa}

Torna-se óbvio, neste estágio do pequeno resumo que fizemos da vida científica de duas noções, que mediação (mediações) e uso(s) não diferem um do outro tanto pelos objetos aos quais se referem, mas pelo efeito de perspectiva que produzem e pela forma bem diferente que consideram o papel ocupado pela comunicação nas práticas informacionais. Podemos concluir que, numa perspectiva comunicacional, as três noções de mediação, prática e uso interagem, mas não sem tensões e paradoxos.

Neste sentido, a leitura de trabalhos de historiadores de livros parece ser especialmente explicativo, pois em certas circunstâncias de seu desenvolvimento, esse campo de pesquisa teve que produzir uma teoria de processos comunicacionais. O problema de fato logo surgiu da relação entre livros e leitura, isto é, entre os objetos de mediação e seus usos. Num campo que havia sido dominado por métodos bibliológicos, voltados para a análise dos objetos e inventários quantitativos, os estudiosos que estavam cientes da problemática da história das mentalidades enfatizaram a questão da natureza das práticas ligadas aos usos do livro. Eles buscavam compreender como os objetos, em sua própria forma material, contribuíam para dar forma às atitudes culturais com relação à leitura: “a história dos livros, escreveu, por exemplo, Roger Chartier e Henri-Jean Martin, não pode mais evadir das formas de leitura, parcialmente registradas no objeto em si, a qual define as possibilidades de uma apropriação, mas também parcialmente apoiada pela cultura daqueles que lêem e dão significado, nosso significado, ao que lêem" (1982: 11). Apontava-se que "uma questão central, aquela dos usos e manuseios, aquela das formas de apropriação e 
leitura das matérias impressas" (Chartier: 1993: 80). Mas tal deslize na postura de examinar práticas de leitura não significa que os historiadores se distanciaram da materialidade dos livros ou das formas simbólicas que estes são capazes de instituir. Mesmo se o comportamento atual de qualquer comunidade ao ler definir um regime de norma e senso, este "situa-se na junção entre formas de ler (as quais são ambas individuais e coletivas, herdadas e inovadoras, íntimas e públicas) e protocolos de leitura registrados no objeto que é lido, não somente pelo autor, que indica o entendimento correto de seu texto, mas também pela editora, que determina sua forma tipográfica, seja intencionalmente ou não, de acordo com as rotinas dominantes" (81). As dificuldades que os historiadores tiveram de enfrentar, à medida que não puderam recorrer a uma observação direta de práticas, obrigou-os a apontar com agudeza particular a dialética entre a dimensão material e semiótica dos objetos mediacionais e a dimensão cultural e antropológica das formas de fazer as coisas.

É algo que é muito claramente manifestado pela ampla investigação coordenada por Christian Jacob sobre mundos letrados ("mondes lettrés"), dedicada à análise da elaboração do texto como um objeto (GIARD \& JACOB, 2001) e à metamorfose do leitor (JACOB, 2003). A dimensão tripla (social, técnica e semiótica) do processo mediacional é onipresente nesse estudo e é a razão pela qual os problemas de diferentes abordagens de mediação, dos objetos mediacionais e das práticas sociais podem ser inteiramente formulados. A criação de objetos contribui para registrar formas de prática dentro de formas de linguagem. $\mathrm{O}$ que tem o poder de conferir durabilidade a disciplinas culturais, a relações entre atores e aos valores de uma cultura. O objeto mediacional, como o catálogo ou o mapa, dá existência a mediadores dentro de instituições e contribui para representar formas de fazer que fingem governar as normas de uma cultura. Entretanto, a vida histórica das práticas sociais enfraquece constantemente essas configurações. Conforme Christian Jacob escreve, "práticas se encaixam em certos lugares, chamam certos atores, lidam com certos artefatos, espalham tradições internas. [...] Mediações, procedimentos heurísticos, rotinas de pesquisa, formas de arquivar e explorar conhecimento, idéias e informações que foram obtidas em livros: todas essas práticas foram ocultadas por muito tempo por trabalhos históricos intelectuais e culturais, os quais se ocupam de conteúdos doutrinários e tendências intelectuais em detrimento de formas que as transmitem e gestos que as produzem. Essas formas e gestos são ainda decisivos, pois ancoram conhecimento no tempo e espaço e o envolvem em comunidades instruídas nas quais atores em diferentes posições cooperam nas tarefas mais humildes bem como nas produções mais decisivas" (GIARD \& JACOB, 2001: 31 ).

Os textos citados acima pertencem, a meu ver, a uma tendência intelectual que vai além de fronteiras disciplinares, sendo capaz de estruturar uma abordagem das mediações info-comunicacionais em si mesmas. É totalmente diferente de criar um híbrido de social e técnica. Poder-se-ia dizer que a análise de mediações revela tudo o que as categorias de social e técnica não nos permitem ver.

Tal afirmação é claramente ilustrada em duas áreas de nossa disciplina, a popularização do conhecimento, de um lado, e os estudos da mídia, do outro. Os cientistas sociais prestaram atenção tardiamente à circulação social de objetos culturais. A popularização, que teve papel importante no desenvolvimento de nossa sociedade, foi considerada digna de interesse mais recentemente. Nas análises científicas iniciais dedicadas a ela, a noção de mediação acabou sendo central. O popularizador recebeu o papel de mediador ("o terceiro homem"), responsável por reconciliar uma sociedade partida em duas, pessoas instruídas e ignorantes. Com o desenvolvimento das análises baseadas em conceitos info-comunicacionais (mídia, aparatos, situação de comunicação, documento), as coisas se revelam mais complexas. Primeiramente, longe de reduzir a popularização a uma tradução do conhecimento existente, reconheceu-se que ela constituiu uma forma de mediação que possui seu próprio sentido. Foi então necessário desfazer a confusão entre discursos e práticas de popularização, como quando se supõe que um texto que é voltado para o homem médio deveria na verdade alcançar um público popular. Desta forma, produções de popularização tornaram-se capazes de deter um status próprio, não como refletindo práticas sociais, mas as condicionando. Os múltiplos usos dessas produções (o que eu chamo de policrese) contribuem integralmente para seu significado real. Finalmente, ao considerar com exatidão as dimensões sociais, técnicas e semióticas da mediação, poderíamos questionar a ligação entre aquela comunicação especializada e toda a economia das trocas na sociedade. Ao invés de dar como certo que a popularização é uma simples variante da educação, as pessoas compreenderam que era necessário ligar a ela os vários aparatos que organizam a comunicação sobre ciências em contextos sociais e colocá-la na perspectiva da relação entre política, ciência e indústria. Isto para que o projeto de popularização da ciência conforme foi elaborada do no século 19 começasse a parecer não com um modelo para o estudo da ciência da comunicação, mas com um certo palco, naturalizado, de discurso social sobre o conhecimento.

Trabalhos sobre popularização, documentários científicos e exposições em museus da ciência são produções midiáticas. Eles inserem certos objetos, por vezes complexos, entre atores sociais. Mencionei acima que a análise de usos poderia contribuir para a pesquisa sobre informação e comunicação com a condição de que a noção de objetos técnicos seja especificada em termos de dispositivos midiáticos. Mas como definir o que é uma mídia? A história resumida acima mostra uma direção para responder a essa pergunta. Em nossa disciplina, na França, a noção de mídia é fortemente influenciada pela sociologia política. A questão é freqüentemente manifestada em termos de "poder da mídia" sobre a “opinião pública”, opondo-se à "liberdade do público". Mesmo não sendo incorreta, esta forma de colocar a questão é vaga demais para nos ajudar na abordagem dos problemas da informação e do conhecimento. Recorro 
a dois exemplos, as noções de "recepção" e "contrato", as quais são ambas muito utilizadas nas abordagens da mídia na França. A forma como os sociólogos deram prioridade aos "estudos de recepção" teve o interesse de destacar as práticas de atores sociais. Neste sentido, possuem clara relevância para bibliotecas e web sites, bem como para programas de TV, os quais concentram a atenção de investigadores sociológicos. Entretanto, o fato de construir a questão como uma alternativa entre "mídia" e "recepção" leva à introdução de uma lacuna entre objetos e práticas: o que é mostrado pelo fato de muitos desses estudos se apoiarem no que as pessoas dizem sobre produções midiáticas, separadamente de qualquer real observação dos programas ou dispositivos midiáticos. Na verdade, a própria noção de recepção é bastante problemática. Ela mistura a dimensão logística do processo mediacional com a simbólica. É certo que as pessoas têm de encarar produções midiáticas que de certa forma “recebem" num nível material. Mas tal transmissão material não dá acesso a questões como interpretação, valor, atitudes culturais. O erro deveria então ser considerar a recepção como uma categoria interpretativa e simbólica, já que é somente logística. Alguns processos info-comunicacionais são baseados em interação direta (como discutir uma questão numa conversa), enquanto outros são moldados por formas midiáticas, no sentido de que exigem a criação de objetos materiais que também são textos, tais como uma apostila, um filme ou um livro. No último caso, a questão real é saber quais são as condições de manifestação e interpretação. Portanto, a idéia de que as pessoas devam receber uma mensagem (e não somente um objeto) ou, ao contrário, que devam ser totalmente livres, deixa passar a interação comunicacional e sua parte informacional.

Isto é claramente demonstrado por outra noção freqüentemente utilizada, a de "contrato". Uma afirmação freqüente diz que a comunicação é como uma relação contratual: as pessoas que interagem devem concordar implicitamente com um conjunto de regras de troca. Tal idéia deixa passar a complexidade da relação entre mediação como um processo e mídia como dispositivos de comunicação. Quando as pessoas lêem um livro, elas não fizeram um contrato com o autor, nem as pessoas que visitam uma exposição o fizeram com o designer. Ambas confrontam-se com uma produção midiática, criada por meio de diversos aparatos, a qual exige delas uma participação. Primeiro, ela envolve as pessoas em ambos os níveis intelectual e físico; segundo, ela oferece uma variedade de sinais para interpretação. O que acontece depois não pode ser completamente previsto. $\mathrm{O}$ que ocorre numa situação midiática é em grande medida incerto, mesmo que não dependa do que os dispositivos e situações de comunicação permitem. Portanto, não há propriamente um contrato, porque nem antes nem depois das trocas pode-se fechar o processo comunicacional acerca de qualquer entendimento cruzado garantido. A comunicação mediatizada por objetos é caracterizada por uma descontinuidade estrutural. Algumas pessoas têm a intenção de comunicar, as mesmas ou outras pessoas personificam essa proposta no ato da escrita, outras con- tribuem para a produção de dispositivos, outras colocam esses dispositivos em prática e lhes dão vida e sentido. Todos esses estágios estão obviamente ligados, pois cada mediação antecipa e condiciona as seguintes, mas o processo inteiro é inevitavelmente cheio de heterogeneidade e incerteza. De acordo com a frase de Davallon, "a orientação do processo de recepção permanece probabilista" (DAVALLON, 1999: 78).

\section{Uma economia renovada de escrita}

Venho delimitando a reflexão, até agora, num nível algo geral; gostaria de finalmente evocar como uma dialética tão complexa entre mediação, prática e uso funciona no universo particular da escrita. O domínio dos textos escritos possui de fato a particularidade de permitir o registro material de posturas culturais e retira dessa capacidade uma força particular nas práticas de programação. Como nota Jacques Fontanille, o objeto da escrita "carrega, em sua própria morfologia, modalidades que condicionam o que o usuário pode fazer" (2005: 198), com a conseqüência de que "configura provisoriamente e localmente formas mais amplas de vida" (199). É o motivo pelo qual o domínio das práticas de escrita é um caso particularmente interessante para se estudar a relação entre mediação e uso, pois lidamos com dispositivos mediacionais que carregam uma informação e manifestam um significado através de sua dimensão semiótica, e ao mesmo tempo impõem uma limitação e moldam uma prática através de sua ação física. Conforme microcomputadores, editores de texto e redes foram inventados, pudemos ver novas formas de escrita surgindo. A comunicação mediada por computadores é um motor potente para as formas de escrita. Como ela possibilita uma mediação industrializada e de larga escala de textos escritos, ela atrai e explora de uma forma particular e poderosa o desenvolvimento de usos sociais. Como organizar as idéias sobre todas essas mudanças?

Gostaria de enfatizar primeiramente a necessidade de uma abordagem semiótica precisa da escrita. A escrita, como muitas mediações comuns, é freqüentemente mal compreendida. Ela deve ser a serva da palavra. Entretanto, mesmo que possa tornar a linguagem visível (CHRISTIN, 1995), ela possui sua própria organização. Os textos escritos não são somente feitos de palavras, eles necessitam de suportes materiais, com seus valores simbólicos e utilizam códigos espaciais. Eles aparecem como imagens e jogam com estruturas de disposição e tipografia (SOUCHIER, 1998; BÉGUIN-VERBRUGGE, 2006). Neste sentido, a escrita alfabética que usamos na transcrição de nossas línguas é somente uma das possíveis formas de escrita, a qual explora muitos outros meios para manifestar o pensamento. Além disto, mesmo em nossas civilizações as características alfabéticas interagem constantemente com formas figurativas de escrita, como as pictográficas e ideográficas (o que é muitas vezes chamado aproximadamente de "ícones").

Isto deve nos incentivar a enfatizar a importância de uma forma específica de mediação, a memorial. Não é totalmente exato apresentar as redes informáticas como 
um mundo radicalmente novo, capaz de instituir uma lógica diferente de comunicação, chamada, por exemplo, de "lógica computacional" (BACHIMONT, 2000). Não devemos negar que a ciência da computação criou novos suportes para a escrita, com base em códigos digitais que nos permitem comandar as máquinas. Mas o código digital define somente o nível mais profundo da mídia. Esta funciona através da exploração de formas muito antigas de manifestação. Obviamente, ele possibilita novas formas de mediação; mas tais processos inovadores apóiam-se constantemente na memória social dos usuários, isto é, no conjunto mais amplo de formas que toda a história das sociedades vem progressivamente constituindo. Pois a ciência da computação não deve ser reduzida à engenharia de software. Seu incrível sucesso deriva da habilidade que demonstra em adotar e adaptar as mediações de cultura existentes à capacidade de industrializar know-hows herdados do livro, da página, do manual, etc. Se planejarmos compreender em que medida a mídia condiciona os usos, devemos nos lembrar da atividade permanente de transposição e transferência de uma enorme experiência de conhecimento adquirido sobre as formas de mediação. Não é absurdo dizer que a ciência da computação tornou-se uma indústria de reciclagem de mediações. Há somente duas limitações: de um lado, o fato de que assimilar um objeto mediacional não implica automaticamente em dominar o significado do ato de mediação; de outro, o fato de que os softwares difundem constantemente em vários domínios disciplinas intelectuais que haviam sido elaboradas e concebidas em contextos restritos.

$\mathrm{Na}$ base de tais precauções, podemos considerar a questão de rastro e rastreamento. A escrita depende dos rastros. Ela segue registrando em vários suportes mensagens que são ao mesmo tempo formas de organizar o conhecimento. A página, o sumário, o catálogo são disciplinas informacionais personificadas em objetos materiais. Mas a noção de rastro é muito ambígua e pode nos enganar. De fato temos a impressão de que o texto escrito carrega o rastro dos usos, de forma que parece fácil coletar esses rastros e então chegar à própria vida social. Mas as coisas são mais complexas, pois todos os níveis de mediação mencionados acima estão envolvidos na análise dos objetos escritos. Os rastros escritos não são reflexos puros da realidade. Eles são enunciações, isto é, formas de posicionamento no mundo e de moldar o significado. São concebidos de forma a possibilitar a leitura, de forma que devem referir-se a certas condições de transmissão, publicidade e interpretação. Isto é bastante óbvio quando alguém toma um texto que foi escrito num contexto privado e o dissemina amplamente ou quando desfaz em pedaços um discurso estruturado: duas formas de violência, muitas fezes feitas de forma impensada, que o processo de "cortar e colar" torna fácil. Os textos escritos são o produto de uma enunciação editorial, uma forma de permitir a leitura num suporte, num contexto, de acordo com um universo de publicidade. O fato de um objeto escrito conter rastros materiais e ter a capacidade de transportá-los não significa que deva ser em si mesmo um rastro puro (um índice puro) do social. Não se pode negar que, até onde textos escritos produzem rastros, eles podem ser usados, explorados, transferidos para outros contextos, combinados e que a ciência da computação dá um poder renovado a tal engenharia industrial dos rastros.

As considerações acima nos permitem reconsiderar em termos info-comunicacionais a relação entre mediação e uso na escrita em redes. O que nos traz mais uma vez à questão política da noção de uso. Na discussão que teve com Foucault, De Certeau concordou com a importância dos aparatos que limitam nossas práticas; mas, ao invés de assimilar os aparatos a uma sujeição ("assujettissement"), ele queria tornar visível a criatividade das práticas sociais. O uso é como as pessoas que não tem o poder conseguem desenvolver seu próprio universo: o que o teórico da invenção da vida diária manifestou através de uma antítese entre estratégia, a força de pessoas fortes, e tática, a força de pessoas fracas, que aprenderam a jogar com limitações. Para ele, ler é apropriar-se, uma atividade que mostra a inteligência daqueles que lidam com a dominação a fim de inventar um espaço para sua manifestação. Esta idéia é chamada de "economia da escrita”, “économie scripturaire " (DE CERTEAU, 1990: 195-224). Acredito que a idéia pode ser hoje revitalizada por meio de uma análise das mediações que estão propriamente ligadas ao processo de informação e comunicação, conforme evocados acima.

A noção de economia da escrita parece ser tanto confirmada quanto profundamente transformada pelo desenvolvimento da comunicação mediada por computadores. Admite-se agora que a oposição entre escrita e tela é relevante, porque o que caracteriza a comunicação em redes é a forma como ela opera uma transferência contínua de atividades que anteriormente não diziam respeito a produções escritas a formas escritas (Cotte et al., 2007). Em outras palavras, as mídias computadorizadas não deixam de levar a uma escrita das próprias práticas, pela maneira como procedem ao registro dos rastros de usos. Elas contam com as contribuições escritas e realizam tratamentos nela. Portanto, a economia da escrita não se baseia somente numa lacuna entre a escrita e a leitura, mas cada vez mais numa lacuna entre diferentes níveis de escrita, dividindo os atores que moldam os formatos da escrita e os que preenchem esses formulários. Por exemplo, uma plataforma participativa, um blog, um web site que coleciona cadernos de viagem torna possível uma grande variedade de diferentes produções escritas, de pessoas cujo status é muito heterogêneo. Mas tal processo contributivo só é possível dentro de formulários que foram elaborados por projetistas de software e que são cada vez mais padronizados.

Propus, juntamente com Emmanuël Souchier (1999), a noção de arquitexto de software para designar tal fenômeno. Softwares de arquitexto são um tipo de escrita da escrita. Quando se escreve num deles, alguém já escreveu antes de você os formulários nos quais você elabora um texto. A partir do momento em que criamos o termo, os arquitextos vêm proliferando constantemente de forma surpreendente demonstrando seu poder extra- 
ordinário. Arquitextos moldam as formas (editores de texto, apresentadores), a troca de correspondência (email, bate-papo), a recuperação de informações (ferramentas de busca), as relações intertextuais (leitores RSS), etc. Resumindo, os arquitextos são objetos de software que seguem industrializando a capacidade das formas escritas de moldar práticas, como explicado acima, levando estas condições numa economia de escrita renovada. Uma economia que pode ser resumida num paradoxo. Um crescente conjunto de meios de expressão que no passado estava reservado a profissionais torna-se utilizável por amadores, tornando visível uma massa de usos culturais. Mas tal expressão coletiva é cada vez mais formatada por ferramentas que apóiam certas formas de mediação em detrimento de outras, tendo conseqüências na economia simbólica, não somente de tal prática individual, mas da cultura como um todo.

Finalmente, ilustrarei esses fenômenos com um exemplo que tiro de um projeto coletivo de pesquisa atual, o qual pode mostrar até que ponto as relações entre mediação, prática e uso estão sendo redefinidas hoje. ${ }^{1}$

Esse projeto de pesquisa trata da análise dos rastros da mediação editorial em agregados textuais amplos na web. Uma das principais tendências da assim chamada "web 2.0" consiste na coleta de rastros de uso e na produção de "cartografias" e "mapeamentos" que devem representar redes sociais, atividades coletivas e comunidades de prática. Para nós, pesquisadores da ciência da informação e comunicação, esses dispositivos de representação são uma forma particular de mediação, mas não são sempre apresentados como tal pelas pessoas que os projetaram. Alguns desses projetistas, dentre os mais populares, apresentam a web como um espaço fortemente heurístico de conhecimento sobre usos sociais, porque se referem a uma noção de rastros que assemelham as produções escritas a um tipo de pacote de práticas. Chegam a anunciar uma etnografia da web com base em tal coleta de rastros.

Os processos sugeridos por esses projetos são, na verdade, muito complexos e diferentes. Às vezes, a produção de modelos para a escrita tem a função de estimular a produção de textos, às vezes as operações de software são tratadas automaticamente, como por exemplo, os links out $\mathrm{e}$ in em sites, às vezes textos diferentes que foram produzidos para diferentes fins misturam-se num corpus único, às vezes usuários comuns se envolvem na produção de palavras-chave, às vezes diferentes tratamentos computacionais e estatísticos são dados a rastros escritos, etc. Todas essas operações levam a produções formais, tanto técnicas quanto semióticas, que tomam a forma de listas, "nuvens", “cartografias”, ícones, mas também a sinais de navegação que dão acesso a diferentes textos disseminados ou, contrariamente, à reprodução de textos externos dentro de sites agrupados. Por trás da aparência de uma compreensão imediata das práticas, a análise aponta um conjunto complexo e denso de mediações. Mas tais práticas, que gradualmente se espalham por qualquer área de informação, da mais comercial à mais ativista, são interpretadas em discurso por seus autores: nos dizem que a questão seria a comunidade, autoridade, popularidade. É uma qualificação informacional espontânea e ideológica de uma prática que consiste na manipulação de fragmentos textuais. E ainda assim é notar que tais práticas gradualmente chegam ao campo da pesquisa aplicada nas ciências sociais, já que devem possibilitar uma nova forma de sociologia implementada - a qual não deixa de ser criticada pelos indivíduos que vem há muito tempo alertando as pessoas quanto à complexidade de conclusões estatísticas. Na verdade, é o prestígio dos processos midiáticos - e também o fato de que a mídia, ao invés de ser considerada como uma mídia, é vista como uma "tecnologia da informação" -- o que legitima essas práticas e afasta, como deveríamos em qualquer análise estatística, a crítica de como os textos e dados são produzidos e, então, sendo capaz de dar uma proporção correta à sua interpretação.

Para pesquisadores das ciências da comunicação, essas operações são interessantes, mas como um tipo de mediação editorial que é realizada em certos textos de status diferentes. Portanto, é necessário compreender o processo que exige, analisar as formas midiáticas e textuais que as tornam possíveis e compreender as transformações semióticas que são realizadas em objetos escritos. De forma resumida, analisar a economia da escrita que está em ação nessas diferentes operações. Finalmente, voltamos mais uma vez à política. O esforço de distanciar-se das metáforas da rede, do mapa ou da indexação social é necessário para fortalecer a ciência da informação e comunicação a fim de fazer uma contribuição específica para a análise dessas relações renovadas entre mediações e usos. É bastante diferente de outra escolha, que deveria ser a de apoiar uma sociologia selvagem, baseada no fato de colocar em equivalência todos os tipos de escrita e a justificativa da idéia de que deve ser possível realizar um rastreamento informacional de qualquer prática através da Internet.

\section{Notas}

Projeto ANR Tramedweb gerenciado por Jean Davallon com um grupo de pesquisa de Avignon (LCC), Lille 3 (Geriico) Paris 4 Celsa (Gripic) e Paris 10 (MoDyCo).

\section{Referências bibliográficas}

BACHIMONT, B. «L'intelligence artificielle comme écriture dynamique: de la raison graphique à la raison computationnelle », dans J. Petitot et P. Fabbri (dir.), Au nom du sens: autour de l'œuvre de Umberto Eco, Paris: Grasset. 2000. p. 290-319.

BADIR, S. «La sémiotique aux prises avec les médias », Visible, 2007, n. 3, p. 173-189.

BEGUIN-VERBRUGGE, A. Images en texte, images $d u$ texte: dispositifs graphiques et communication écrite. Villeneuve d'Ascq: Presses du Septentrion. 2006.

BONACCORSI, J. À paraître. Le devoir de lecture: médiations d'une pratique culturelle. Paris et Londres: HermèsLavoisier. 2009. 
COTTE, D.; CHERVIN, J.; DESPRES-LONNET, M.

«La sémiotisation d'une pratique professionnelle: l'activité de montage numérique dans l'audiovisuel » dans C. Tardy; Y. Jeanneret (Orgs.), L'écriture des médias informatisés: espaces de pratiques. Paris et Londres: Hermès. 2007.

CHARTIER R.; MARTIN, H.J. Histoire de l'édition française. Paris: Promodis. 1982.

CHARTIER, R. « Du livre au lire », dans Pratiques de la lecture, Paris: Payot. 1993, p. 79-113.

CHRISTIN, A.-M. L'image écrite ou la déraison graphique. Paris: Flammarion. 1995.

DAVALLON, J. L'exposition à l'œuvre: stratégies de communication et médiation symbolique. Paris: L'Harmattan. 1999.

DAVALLON, J. La médiation: la communication en procès ? MEI, 2004. n. 19, p. 37-58.

DE CERTEAU, M. [ 1 ère éd. 1980]. L'invention du quotidien, vol 1 Arts de faire. Paris: Gallimard. 1990

DUFRENE, B.; GELLEREAU, M. « La médiation culturelle: métaphore ou concept ? dans Émergences et continuité dans les recherches en information et communication, actes du 12 è congrès de la SFSIC, Paris: Jouve. 2001, p. 233-240.

FONTANILLE, J. « Du support matériel au support formel », dans M. Arabyan. et I. Klock-Fontanille, dir. Lécriture entre support et surface, Paris: L'Harmattan. 2005, p. 183-200.

FLICHY, P. L'innovation technique: nouveaux développements en sciences sociales. Paris: La Découverte. 1995.
GIARD, L.; JACOB, C. Des Alaxandries. 1 Du livre au texte. Paris: éditions de la BNF. 2001.

JACOB, C. Des Alexandries. 2 Métamorphoses du lecteur. Paris: éditions de la BNF. 2003.

LABELLE, S. La ville inscrite dans « la société de l'information »: formes d'investissement d'un objet symbolique. Thèse de doctorat, Université Paris 4. 2007.

LATOUR, B. « Ces réseaux que la raison ignore: laboratoires, bibliothèques, collections », dans M. Baratin et C. Jacob (dir.) Le pouvoir des bibliothèques: la mémoire des livres en Occident, Paris: Albin Michel. 1996, p. 23-46.

MARIN, L. Le portrait du roi. Paris: Minuit. 1981.

PERRIAULT, J. La logique de l'usage: essai sur les machines à communiquer. Paris: Flammarion. 1989.

QUERE, L. Des miroirs équivoques: aux origines de la communication moderne. Paris: Aubier-Montaigne. 1982.

Souchier, E. « L'image du texte: pour une théorie de l'énonciation éditoriale », Cahiers de médiologie, 1998, n. 6, p. 137-45.

SOUCHIER, E.; JEANNERET, Y. «Pour une poétique de l'écrit d'écran », Xoana, 1999, n. 6, p. 97-107.

SOUCHIER, E.; JEANNERET, Y.; LE MAREC, J. Lire, écrire, récrire: objets, signes et pratiques des médias informatisés. Paris: éditions de la BPI. 2003.

TARDY, C.; JEANNERET, Y. L'écriture des médias informatisés: espaces de pratiques. Paris et Londres: Hermès. 2007.

TUFTE, E.R. The Cognitive Style of PowerPoint. Cheschire (CT): Graphic Press. 2003.

\section{Sobre o autor}

\section{Ywes Jeanneret}

Yves Jeanneret é professor de ciência da informação e comunicação da Universidade de Avignon, na França (Université d'Avignon et des Pays de Vaucluse). Investiga principalmente o campo do compartilhamento de conhecimento e da construção social de objetos e valores culturais. É especializado nas várias formas de mediações de escrita, tanto nos dispositivos tradicionais quanto nos mediados por computadores, e na epistemologia dos processos de comunicação. Já publicou, notadamente: Écrire la science, PUF, 1994, Y a-t-il (vraiment) des technologies de l'information, Septentrion, 2000 e Penser la trivialité: la vie triviale des êtres culturels Hermès, 2008. É o editor do periódico francês Communication \& Languages. 